\title{
Insights on the field of geography education from a review of Masters level practitioner research
}

\begin{abstract}
In this paper I report on a review of over 400 Masters level dissertations in geography education completed since 1968 at the UCL, Institute of Education, London. The aim of this review is to understand how the field of geography education has been understood and problematised by practitioners within the field. Unlike the Road Map report on Geography Education Research which reviews geography education research from a strategic perspective, this research explores the field from the perspective of the practitioners and therefore asks what are the issues that concern practitioner researchers. Whilst practitioners add an important perspective on the field, their concerns are often not evident in the published literature. This paper argues that the practitioner focus on "problems of the day" is a key dimension that needs to be more widely recognised in the academic literature. This goes beyond a simple definition of research as describing "what works" in education, but as part of an ongoing dialogue between research and practice that is characteristic of a practical field of research enquiry. The research contributes to our understanding of how the field of geography education (within specific contexts) is experienced and problematised by practitioners.
\end{abstract}

\section{Key Words}

Geography education research, practitioner research, Masters dissertations, dissertation research, practice. 


\section{Introduction}

The International Geographical Union's Commission for Geography Education's new Charter on Geography Education (IGU-CGE, 2016) highlights the important role that policy makers, geographers and practitioners have in defining and developing the field of geography education. Similarly, papers that review the state of geography education also highlight the important role of policy makers, politicians and professional associations in defining the field (Bednarz et al 2013, Butt and Lambert 2014). However, less is known about how practitioners view geography education research and whether it meets their needs. In a practice-orientated field like geography education, research can be seen as an ongoing dialogue between practitioners and academics and as such, the view of practitioners is paramount in understanding the field. Whilst influences from policy makers are undoubtedly important, the rise of concepts such as curriculum making emphases the role of the practitioner and as such necessitates a refocus on practitioners' concerns with the field.

This paper draws upon a review of research conducted through the Masters in Geography Education at the UCL Institute of Education (IOE), London UK. The programme, established in 1968 and run continuously since then, has had over 400 dissertations completed in geography education, the majority conducted by practitioners. The review explores the topics that practitioners have used as the focus of their dissertation research as a way of understanding the concerns that practitioners have of the field of geography education. This is not to suggest that GER should focus on more smallscale research, but that the field should pay more attention to the valuable research that is being undertaken at a practitioner level and reconsider what that tells us about the issues worthy of research.

\section{The lack of practitioner influence on geography education}

Marsden (1980) argues that the geography curriculum is a result of what has gone before, as trends are often a reaction, or a response to previous developments. Indeed, historical reviews of geography education have noted key movements and shifts within the field, but have acknowledged that most of these have been driven by external influences from outside geography education (see Bednarz, Heffron \& Huynh 2013). For example, within the English context, Walford (2001), Rawling (2001), and Graves (2001) have traced the development of school geography. Walford (2001), analysing school geography from 1850-2000, observes that it has been influenced by broader changes and developments in pedagogy such as progressive notions of teaching and learning. 
Graves (2001), whose work focuses on school geography textbooks from the same period, makes similar observations stating: "[Geography school] textbooks tend to follow society, rather than lead it" (Graves, 2001: 157

Within geography education, however, there is evidence of change occurring from within the field, but not directly by practitioners. Goodson (1987) notes how sociological accounts of the making of school geography reflects its social construction highlighting the role of key influential individuals, the lobbying role of subject associations, and the relationship between status and access to resources. Although criticised as somewhat partial accounts (see Morgan and Lambert 2005) detailed sociological histories and commentaries of school geography reflect the "contestation and compromise" (Goodson 1987) that have taken place in forming the field (Butt 1987, Walford 2000, Rawling 2001, Lambert 2004, Lambert and Morgan 2005). These accounts reveal that individuals can exert strong influence over the construction of a school subject. However, as Rawling (2001) notes, their perspectives are not value-free but are ideologically driven, and as Marsden comments they reveal only part of the story of the development of the field, focussing on individuals and events rather than fruits of scholarship in the field (Marsden 1984). The individuals in Rawling's account are often representatives of the geography education or education community, but there is little representation from practitioners in the field. Likewise the scholarship referred to by Marsden (1984) tends to stem from geography educators in higher education institutions or professional associations rather than practitioners.

In fact, developments within geography education are often driven from outside of the field. Boardman and McPartland (1993a, b, c , d) wrote a series of four articles on "A Hundred years of geography teaching" to mark the centenary of the Geographical Association. These articles trace the developments of geography teaching during that that period. Whilst their account traces the various key figures, education acts and initiatives, they do not mention the impact of geography education research or of work undertaken by practitioners. Noting key developments that have influenced school geography in England, such as the Raising of the School Leaving Age (ROSLA) and the development of the School Council Projects, Marsden (1997) argues that these developments have elevated the influence of social or educational concerns within education, resulting in the reduction of geography within geography education. He attributes these changes to movements outside geography education, with relatively little impact from inside the field. 
Indeed, if one is to review the impact of geography education research conducted by practitioners on the field, then the results are disappointing. Lambert's (n.d.) summary of the contribution of geography education scholarship suggests that the insights are mainly peripheral and organisational, and do not reflect significant theoretical insights into how young people learn geography, or the pedagogically robust ways of teaching geography. Roberts's (2000, and see also Lambert 2015) review of GER highlights that there has been research on children's thinking, on resources (texts, maps, pictures), on curriculum policy and documents. Roberts notes that there have been relatively little research on actual practice in the classroom and in the field: on the processes that bring together the teachers' subject knowledge, professional knowledge, and on the way teachers and students interact in geography - the most neglected, perhaps because it is the most difficult (for example, in terms of access and ethical issues) (Roberts, 2000 and 2014). Contrasting the outcomes of this research with the impact of developments and influences from education research would seem to suggest that geography education research conducted by practitioners has made a limited contribution to the field.

This limited contribution is not unique to geography education, but is a recognised feature of practitioner research. Practitioner research is often small scale, under-funded, and sometimes under theorised (Bednarz et al 2013; Brooks, 2015; Lambert, 2015). However, one of the biggest barriers to its inclusion into the canon of published research is that it is considered methodologically weak. Roberts (2015) notes that practitioner research whilst often meeting two Oancea and Furlong's (2007) three 'domains of quality' (theoretical and practical), it often falls short of the third domain of technical. Practitioner research often fails to meet the criteria of accountability and impact. This is no doubt tied up with the very nature of practitioner research: that it is necessarily small-scale and limited in scope. Morgan (2015) describes it as being reduced to a form of "Methodism": an overreliance of particular aspects of methodology without taking into account the scale or scope of what is being researched. In other words, it can be difficult for practitioner research to meet the criteria required for it to be considered robust enough for inclusion into the field.

However, similar criticisms have also been heralded at the range of geography education research, possibly due in part to the apparent youth of the field (see Lambert 2010), and the limited availability of large-scale funded research projects (as alluded to in the US Road Map Report on Geography Education Research). However, an alternative perspective could argue that practiceinspired scholarship has made significant contributions to the field but one that has not been recorded in histories of geography education. For example, one could look th the growth of enquirybased approaches to geography education, which has roots within constructivist learning, and within 
the exploratory tradition of geography have been fruitful areas of development within geography education. Noteworthy here are the Schools Council projects' emphasis on enquiry and teacherbased curriculum development (see Naish, 1997 and Rawling 2001), and the landmark publications of Robert's (2003 and 2014) work exploring different approaches to enquiry within geography education. Indeed these approaches can be described as having roots in the geographical tradition of exploration and discovery. This practically-orientated form of scholarship has emerged through concerns with practice and quality in geography education research, but is somewhat hidden in the accounts of the development of the field, and often requires the advocacy of an academic geography educator to promote its wider dissemination.

\section{Is practitioner research a feature of Geography Education Research?}

To identify the features of geography education research, it is useful to start with identifying the field which it serves. Lambert argued:

"If there is a field of Geography Education Research, it surely needs to be more substantial than education research with a geographical hue. It seems to me that Geography Education Research is concerned with two big ideas, geography and education, and how they are related. What this means most obviously is the study of how geography contributes to education." (Lambert 2010: 85)

Adopting Lambert's definition affects how we view practitioner research within geography education. Changes in higher education and initial teacher education, have resulted in an increase in practitioners undertaking Masters level work in geography education, as part of their initial certification. In some jurisdictions a Master's degree, with an aspect of practitioner research, is a necessary requirement for teacher certification. This can mean that there is a proliferation of practitioners conducting small scale research into geography education (Brooks 2010). However, practitioner research tends to be orientated differently to academic research (see Sachs 2003), and when part of an accredited course, it can be constructed to reflect certification guidelines. This can create barriers to its inclusion in the field as research of this kind has different tests of validity and reliability. Nevertheless, its roots in practice make it a valuable addition to our understanding of the field, and in particular to how practitioners view the field.

The US Road Map Report on Research in Geography Education (2013) takes a different perspective, by focusing on two key questions that are pertinent to the US context: 
- What areas of research will be most effective in improving geography education at a large scale?

- What strategies and methodologies can relevant research communities develop and adopt to maximise the cumulative impact of education research in geography?

These questions were developed through an assumption that the lack of success in school geography in the USA is a threat to "social, political and economic well-being" and so the focus of the report is on how to improve geography education in the USA. The Road Map project has a specific but somewhat localised agenda and key goals and audiences. The review's purpose was to support the strategic improvement of geography education in the US, and the thirteen recommendations in the report reflect this objective, by calling for large scale, funded research into instruction materials and strategies and a connected dissemination strategy. The report articulates a strategic vision for geography education in the US: to identify "what works" and the necessary mechanisms to roll out and implement this vision. The scale and context of geography education in the US makes this a sensible strategy. The review however, downplays the importance of practitioner research within the field. The focus on research instruments that can be replicated in a variety of contexts privileges an instrumentalist approach to educational research, one that may be far removed from the concerns of geography education practitioners.

This approach is counterbalanced by Roberts (2010) who argues that evidence gathered from both qualitative and quantitative research can be helpful as they provide different insights on teaching and learning. Roberts is also somewhat sceptical of "what works" research. Her position is that teachers have craft knowledge based on experience and would need to relate that experience to research findings. Ultimately, even if the research outcomes are clear, Roberts argues that their implementation is still a matter of judgement on the part of teachers: "not a cook book but a resource" (2010: 94). She also highlights that accessibility of research is best achieved when teachers get involved.

There is, then, a need to consider the particular perspective that practitioners bring to the field of geography education research. However, there is also a need for caution. Morgan (2013) highlights that there are often methodological problems with how the research is conducted. Whitty (2016) has also cautioned of the pitfalls of being selective from research that lacks rigour. Added to this, gaining access to practitioner research is not easy. Much practitioner research is not easily accessible, as much of it remains unpublished. However, until recently (2014), research conducted as part of a Masters degree in Geography Education at the UCL Institute of Education (IOE) was widely available through the Newsom Library and academic department. This body of practitioner research 
spans 45 years, and although largely conducted in England, represents a significant body of practitioner research from which to draw. The methodological concerns notwithstanding, exploring the topics covered by this research offers a window into the perspectives and concerns of geography educators.

\section{Dissertations from the MA in Geography Education}

The MA in Geography Education was established by Norman Graves at the UCL Institute of Education in 1968. Kent developed a distance learning version of the programme in 2001 (Kent, 2004)'. The Masters degree is open to anyone interested in geography education but attracts mostly practitioners who study part-time. It can be studied entirely at a distance, but some modules offer optional face-to-face sessions for students who are able to come to London. The initial programme and the subsequent developments reflect Graves's vision and rational for the establishment of the degree. Graves argued that it was important to look beyond the foundational disciplines of education and to develop:

"a course in which the problems of teaching and learning their own subject, were specifically dealt with in the light of research findings, which might be derived from the disciplines of education or form any other useful source". (1989: i)

The strong relationship between research and practice remains a feature of the programme. The dissertation is an important opportunity for students to conduct research into an area of interest, often into issues that have arisen through their practice as geography teachers. The dissertation is a piece of extended writing (20,000 words) around a piece of (often empirical) individual research. Students are also given the opportunity to write a shorter piece of research, a report (10,000 words) in place of the dissertation, but this has been rarely taken up. The format of the dissertation follows a typical research report structure, requiring students to situate their research within the literature, to justify the methodological approach and the research design, and to outline and discuss the research findings, conclusions and limitations. All students' research is required to undergo ethics approval.

The characteristics of the students have changed over the years. Colleagues with a long term association with the programme have noted that students are now more likely to be full-time teachers, in the early years of their career (typically less than 5 years). Some recent students have been pre-service teachers taking the degree as a pre-requisite before starting an initial teacher education programme. Formerly, in the 1980s, students were more experienced teachers 
undertaking a sabbatical year funded by their local education authority. Lambert (1989) notes the decline of students in this category in his 1989 review of dissertation research. The MA has also attracted a significant number of international students. In the early years of the programme, international students were often funded by their government and returned to their home country, sometimes with a remit to disseminate what they had learnt. In more recent years, international students have been self-funded and are sometimes working in international school contexts.

The importance and value of the research conducted on this programme has long been recognised. Francis Slater (1989) stands out as an advocate of disseminating the findings of the practitioner research developed under the programme. Graves (1989) acknowledged that the first review of research conducted on the programme was Slater's idea and she was a great support to the project. Slater also edited the Monographs on Research in Geography education published by the IOE between 1989 and 1997. In the first monograph, Slater (1989) observed that the pattern of research was showing a greater emphasis on children's learning in geography, geography curriculum research and development, and on values in geography. She also highlighted that post-modern geography seemed to be an area that was under-represented. Reflecting her title "do our definitions exist?", she questioned whether the Habermasian categorisation of research : positivistic, interpretivist and action research, were useful in the application of practitioner research, as the "Categories act as conveniences for thinking which need to be re-examined from time to time for their actual meanings" (Slater 1989: 8). She therefore emphasised that the value of small scale practitioner research projects were that they helped illustrate a more detailed understanding that goes beyond more generalised accounts:

The general concepts cannot convey all of the light and shade and complexity of the individual instance (Slater 1989; 7)

Both Graves and Slater observed that research conducted on the MA programme were likely aligned to "problems of the day" which in the early years of the programme focussed on the teaching of the "New Geography" and other developments in the academic discipline such as welfare and humanistic geographies. Slater's later commentary observed that this trend continued: "Interests shift. Priorities shift. Insights shift." (Slater 1995:6)

However, 45 years after the development of this programme, there is now a significant body of practitioner research, and the opportunity exists to use that body of research to consider what the topics chosen for research by practitioners tells us about their concerns in the field.

\section{The research approach}


At the time of this research (conducted in $2013^{1}$ ), the dissertations totalled 412 . The title page and abstract of each dissertation were photographed. The photographs were then translated into text, either through the use of OCR (optical character recognition) software, or directly transcribed. The data used in this research are therefore limited to the title and abstract of each dissertation. Of the 412 only 2 dissertation abstracts were not available. This was because both copies of the dissertation were unavailable, possibly because permission was refused for the dissertation to be in the public domain.

Once all the titles and abstracts had been converted to text, the analysis process took three stages:

- Stage one was a content analysis - this required highlighting key and common words that occurred throughout the data

- Stage two then sought to categorise the dissertations thematically: so that dissertations on a similar topic were grouped together. Within each category, the dissertations were organised chronologically.

- In Stage three each category of dissertations was then analysed for the forms of problematisation: ie, how had the dissertation author sought to relate the topic of their research to both their context and to the field, ie, how the research was positioning itself in relation to other influences.

Working with the dissertation abstracts and titles did present some difficulties. Not all abstracts contain the same information or are of the same quality, therefore sometimes it was unclear as to how the research was conducted or the findings of the research were not recorded. However, as the focus of this study was on the topic of the dissertation, something that was contained in all of the abstracts and titles, the variable quality of the abstracts is not significant, and the omission of findings or methodological information does not affect the data gathered.

It was however, the case that some abstracts omitted information. For example, I supervised a dissertation conducted in a foreign country, but it was only when I interrogated the abstract that I became aware that neither the abstract nor the title, made reference to the country within which the research was conducted. It may be possible then that the omission of some information in the abstracts may mean that some research should have been categorised differently had the full dissertation been included rather than the title or abstract, but this was not considered significant as most of the abstracts contained sufficient information for a clear identification of topic.

\footnotetext{
${ }^{1}$ After this time, dissertations were no longer stored for public borrowing.
} 
It is also worthy of note that the MA programme has not had a consistent number of students each year, and so it was not always possible to draw conclusions from what is sometimes a limited data set (some years only had 2 or 3 dissertations completed). The dissertations were grouped into 5 year chunks so that changes over time could be observed. In spite of this, there was evidence that some years featured popular topics which influenced the dissertations completed at that time (for example around the introduction of the English Geography National Curriculum in 1991).

Figure 1 illustrates the distribution of dissertations and their relative sector focus. The variation in numbers each year can be attributed to a number of factors including availability of external funding, relative focus on geography within national education systems, and on marketing and recruitment adopted by the programme team. The recent increase in the number of students since 2008 can be attributed to a renewed focus on encouraging students enrolled on a teacher education programme (the Post-Graduate Certificate of Education or PGCE) at the IOE to further their studies onto the Masters programme, combined with the introduction of Masters credits being made available to PGCE students. Issues pertinent to the recruitment of these students onto the programme are discussed in Brooks et al (2012).

\section{"Problems of the day"}

Research conducted on the programme falls into two broad categories of curriculum and pedagogy. Within these broad categories, the following sub-categories can be observed:

- Curriculum

- Relationship to geography in higher education

- Content and arrangement of topics and themes within the school curriculum

- Evaluation of policy initiatives including national curriculum reviews or changes to public examinations

- Changes in assessment and examinations and their influence on the school curriculum

- Pedagogy

- Use of technology within geography education

- Adaption and use of resources (including textbooks and maps) within a classroom context

○ Fieldwork

- Preparing students for examinations 
Research conducted outside the English education system are included within the categories above. Table 2 reflects the number and range of dissertations conducted by international students on the programme, however, these dissertations also focus specifically on aspects of curriculum and pedagogy. The data in Table 2 needs to be treated with a degree of caution. For example, some dissertations (like one conducted in 2005, and another in 2011) contrasted geography education within two countries. In both cases, neither of the researchers were based in either of the countries featured but had extensive experience of them. In other cases, (particularly those conducted in the 1980s), students may have been sponsored by their respective governments and funded to undertake research in their home countries. There are also some dissertations that were conducted in other countries but where this was not specifically mentioned in the title or abstract. References to Wales and South Wales were omitted from the above list, as they are part of the UK.

Taking the data set as a whole, the general trend is for the research to be influenced by broader trends in education (which may of course be influenced by a students' funder or employer). Legislation changes in England such as the development of Common External Examinations, the Raising of the School Leaving Age, or the introduction of a National Curriculum, have an immediate impact on the research conducted (see Table 3). The focus of dissertation topics selected by practitioners is to some extent reactive (in that they are reacting to recent developments), and explores those changes from the perspective of the practitioner. Similarly, the predominant methodological approach of the dissertations reviewed is evaluative. For example, of the 413 dissertations, 97 specifically refer to a "new" initiative or approach; there are 265 uses of the word "evaluate", and 151 uses of the word "review".

Some early dissertations were focussed on reviewing the field. This can be illustrated by the number of historical reviews conducted within the early years of the MA programme $(1973,1974,1975$, 1976, 1979). There have been no historical reviews conducted since 1979.

The strongest trend is for dissertations to explore a development, policy or initiative and to evaluate its impact on geography education. However, over time, the focus of dissertations has become more narrowly defined: exploring the impact of an initiative on one school or one teacher's practice or even on one class; whilst the range of influences explored (either from wider fields of geography or education) have expanded and become broader. The analysis below illustrates this trend and the implications of it.

\section{Pedagogical Change in Geography Education}


With much of the research being conducted by practitioners, it is not surprising that many of the research topics feature innovations, and evaluate their impact or potential impact on the geography classroom. This is best illustrated through the research conducted around developments in technology, most of which adopt an evaluative approach to research design.

Dissertations focussing on technology are influenced by developments from both within and without education, and so reveal the diversification of technologies used. Research in this topic also show the second trend for the research to be narrowed onto individual classroom and teacher experiences. Table 3 illustrates a selection of dissertation titles around technology which have been selected to illustrate this trend. The table does not include all the dissertations that explore technology as there is some repetition in topic, and the relevant technology related words have been underlined.

The selection of titles in Table 3 shows that the interest in visual media has been fairly consistent throughout the MA programme. The focus of the dissertation research has changed as the availability of technology has increased: from still photographs, through to the introduction of colour, television and video resources, to digital technology. However, this is not the only trend. An enduring theme evident within these titles (and the accompanying abstracts) is how this technology can be used. This can be observed through the prevalence of "use" words: "use" ( $n=718$ ), "value" ( $n=266$ ), "accessibility" ( $n=30$ ). It is also important to note the prevalence of geography classroom within these research title. Even when using fairly generic questions, the research issue is to evaluate the potential for geography education, with the emphasis on the geography (note the references to distant places ("third world") or glacial processes and landforms). These evaluations reflect the primary concerns of geography educators, responding to changes in society and how they may benefit geography education.

Within the research conducted around technology, some dissertations have also focussed on geography specific technology (see Table 4). This selection of dissertation titles shows a concern with how to teach with Landsat imagery, which was popular from 1978 through to 1988. Even with this fairly small sample, it is possible to see how the research focuses have varied from different age groups and geographical themes. More recent dissertations shift the focus from Landsat imagery to GIS illustrating how the changing world (in this case the availability of GIS for schools) can influence the concerns of the practitioner. Behind these overall trends, there are other influences to note: the 
increased accessibility of these technologies and their inclusion in curriculum or assessment schemas. Satellite images were specifically mentioned in the Original Orders of the Geography National Curriculum 1991), and in more recent years, GIS has become a feature of public examination specifications in England. In these incidences, practitioner concerns (of how best to use this technology to improve teaching and learning) are in tandem with, and arguably influenced by changing contexts of, geography education. The practitioners appear to be using the research requirement for their Masters degree as an opportunity to explore pertinent and timely practicebased issues, highlighting the primary concerns of the field, but crucially through the eyes of the practitioner.

Finally, within this theme of technology, a key area of interest has been the introduction of computers into geography classrooms. Initially dominated by the phrase: Computer Assisted Learning and through various reincarnations of terms used to describe the internet, we can see how the dissertations reflect changes in broader society (see Table 5), as well as research interests of the IOE tutor team (Ashley Kent was interested in the field of Computer Assisted Learning, (CAL).

It is interesting to note here that despite the 'creep of technology', the fundamental concerns of these dissertations, as reflected in the titles and abstracts, are evaluative in nature: determining how technology can be best used to improve the quality of geography education. However, this selection of dissertations also illustrate the narrowing of focus on dissertation research over time. For example, the review of CAL for schools in Hertfordshire (a region within the south east of England) (completed in 1981) features a broader research base than the 2003 research on spoken interaction in groups during an internet enquiry (within one school), or the 2010 evaluation of online resources for one ' $A$ ' Level specification. Whilst the range and variety of research topics appears to have broadened the focus of the research has contracted to smaller populations. This suggests that practitioners' research is becoming more inward-looking, and focussed on practice-related issues around the experience of teaching and learning geography.

The trends highlighted above in relation to technology, can also be seen in other dissertation research around pedagogy and resources. Key themes identified also included mixed ability teaching, learning styles, textbooks and other resources. These themes are less well represented across the programme life-span as they move in and out of vogue, but the trend is still evident.

\section{Fieldwork}


Fieldwork is a popular area of interest that students identify when they start their dissertation research (in my experience as a tutor on the programme). Students are motivated by a commitment to the importance of fieldwork and a belief that fieldwork makes a substantial contribution to the learning of geography. Despite this initial enthusiasm, the number of dissertations that feature fieldwork is relatively small $(n=33)$ but consistent over time (1970-79 $n=9 ; 1980-1989 n=11 ; 1990$ $1999 n=7 ; 2000-2012 n=9)$. This small number also reflects the comparative lack of research literature on fieldwork in geography education generally.

It is worth noting that the first dissertation to focus on fieldstudies was also the first dissertation on primary-level education (1972 "Field studies in the primary school"), but since then fieldwork has featured in relation to all phases of schooling. The titles in Table 6 are a selection of dissertation titles, selected to demonstrate how the theme of fieldwork has been adapted to reflect concerns at the time.

In the selection in Table 6, it is possible to observe both the widening of contexts and themes within the field, alongside the recent trend for a narrowing of focus to a detailed evaluation of fieldwork's specific contribution to a select group. We can also see how the research in this area has been problematised in relation to external threats and events: for example two dissertations (2008 and 2009) are a response to the English government's publication of the Learning Outside the Classroom manifesto (2006). Here again we can see that the concerns of practitioners are around quality and the experience of teaching and learning geography. These concerns are predominantly small-scale and within the teachers' sphere of experience and influence. However they also raise concerns that are of much wider significance and are of interest to the wider field, and reflect the need for practitioners to contextualise findings to their own contexts (as outlined by Roberts, 2000).

The selection of fieldwork research raises two interesting issues. First, as the titles indicate they represent a concern with quality: a sense that fieldwork is an integral part of learning geography and a desire to make this the case. In addition, they represent a very localised and small-scale approach to understanding the role of fieldwork. So, whilst building on the important fieldwork tradition in geography the focus is mostly relevant locally.

\section{Discussion and conclusions}

Practitioners undertake research for a variety of reasons, such as for accreditation or due to a desire to improve practice. Most of the research conducted on the MA in Geography Education has been 
practice-orientated, reactive to changes in the field. Practitioner research can be seen as a way of making sense of these changes. The evaluative nature of this research shows a pre-occupation with quality and a consideration of the impact of these changes.

It is worth noting that the trends observed here may be due to the local factors on the MA programme. For example, it is possible to see the influence of tutors on the programme, and their specific interests on the topics chosen for research. Some caution has to be applied here, as it is not possible to show from the data itself that research conducted in particular fields has been influenced by the tutor directly, or that the theme itself was pertinent at the time and so encapsulated interest from the field generally. However, it is safe to assume that tutors' interests will be featured in the teaching component in the programme, and therefore may be of some influence on the students on the programme. Kent identified a number of trends and influences from colleagues (Kent 2006) and how they reflected broader concerns with the field.

It is also important to compare the research conducted on this programme with that conducted on other Masters degree programmes elsewhere. This study has only featured dissertations from one programme. A recent visit to East China Normal University and their Geography Laboratory, suggested that Masters level research here often has more of a focus on developing classroom pedagogy than evaluating it. Reviews of research in other places (see for example Yoshimizu, 2015) reveals that the focus of published research around the world can have particular themes and emphasis. This is not to suggest though that the MA in Geography is a purely English programme. Over the course of the MA programme, a number of dissertations have been completed into international contexts of geography education (see Table 2). The research approach of these dissertations, as with ones that are conducted in England and Wales, is mostly evaluative. However, this particular group of dissertations highlight the variety of research conducted: from the very general: ("Curriculum development in geography with special reference to Hong Kong"; 1975) to the more specific: ("An analysis of geography textbooks in primary and secondary curriculum in South Africa" 1985).

International research is also reflected in events happening in the broader field of education. For example, in 2008, a dissertation evaluated the impact of working in offshore school context ("Cross Cultural Teaching Teams: A Study Into Cooperative Efforts To Enhance Geographic Learning In British Columbia Offshore Schools In China.") and in 2012, another explored the phenomena of pseudoprivate companies running schools ("An evaluative case study of the Kunskapsskolan concept on curriculum making for Geography based on the experiences of curriculum writers at the Learning 
Schools Trust Academies in the United Kingdom"). But as this review has shown, whilst they may be related to trends outside of geography education, the focus of the research is evaluative.

Cordingley (2004) makes an important distinction between practitioners using research and doing research: "Their entry point is improving teaching and enhancing learning and that is where their priority stays. They see themselves as engaging with research but not in it." (2004; 85). She argues that this is because practitioner research is undertaken as a form of professional development, and is focussed around learning goals, drawing upon evidence only taken from classrooms, with the aim of developing practice. Practitioner research offers reflection and challenge to the practitioner, but, she argues, should not be considered as research. In her paper, Cordingley equates the purpose of research, why it was conducted, and how it is disseminated with its contribution to the field. However, in this paper, I have taken a different stance.

By identifying geography education as a practice-orientated field, knowledge creation within this field needs to emerge through a dialogue between geography educators in the academy (who are the main publishers of scholarly work) with practitioners. To characterise one as a producer, and the other as consumer, ignores the important dialogic relationship between theory and practice that is characteristic of a practice-orientated field. However, dialogue has to be two way, and much of the research published in geography education is authored by geography educators in the academy. This is not to suggest that geography teachers should consider publishing academic texts in order to take part in the conversation, but that geography educators need to be more mindful of the concerns of practitioners and ensure that research conducted and published speaks to these concerns, as well as their own.

Townsend (2013)'s distinction between "practice" and "research" is useful here, as she argues that they can be related in a variety of ways: through

- Deriving practical implications from related research

- Conducting practice-focussed research

- Developing practices through research

- Practice as research.

Paying attention to practitioner research gives an important voice to practitioners, which can privilege their perspectives. Indeed, James (2006) notes the value of conducting research in authentic settings, and that a number of outcomes (in terms of publications) have made substantial contributions to the field. Cain (2010), in Music education, notes that whilst practitioner research is 
seldom referred to in other publications, its value is also that it focuses on different types of knowledge (experiential and propositional). Roberts (2015) also recommends Teaching History for a view on practice-orientated research in history education.

The data in this review reveals remarkable consistency in the themes selected for practitioner research, suggesting that the concerns of geography education practitioners are enduring. The data also reveals a high number of evaluative studies and within these, a simultaneous broadening of topic, with a narrowing of both focus and research methodologies. The research outlined in this review could be described as reactionary, evaluative and reflective, often small-scale and highly influenced by context.

So what then are the implications of these findings? Both Slater and Graves noted that practitioners were often concerned with "problems of the day", and that whilst perspectives may shift, these changes are unlikely to be seismic. This review illustrates that for practitioners the fundamental concerns of geography education appear to be fairly timeless. A concentration of topics on issues around curriculum, pedagogy and assessment, and in particular how these relate to geography education, and changing contexts is precisely the sort of research that Graves set up the degree to explore. It is heartening to see that practitioners are consistently concerned with critically evaluating changes occurring around them, that may impact on geography education, and that they are predominantly concerned with issues of quality. It is to be celebrated then that practitioner research features predominantly "chalkface" issues, and that these concerns should be an alert to the wider community, as they are worthy of attention for further research. The focus on chalkface issues, may not correlate to the big questions that occupy academics in the field.

However, it is also instructive to explore what are missing from these accounts. Exploration of the theoretical approaches and terminology used reveals that there are no recurring "meta-theories" of geography education. Research accounts tend to evaluate external influences and legislative changes rather than determining what Lambert (2010) described as "the study of how geography contributes to education." The research through fieldwork (and for that matter other topics) looked at how changes externally could be exploited or avoided through fieldwork practice, but there are few findings here that could inform education beyond the subject. Indeed, there are few studies on geographical enquiry, or on the relationship between academic and school geography (since the late 1970s), that could be seen as adding to our understanding of this in practice.

These findings are significant in two areas. Firstly there is a need to recognise and embrace the major contributions of the field of geography education, and to synthesise these into meta-theories 
that teachers are inducted into through their initial teacher education, and are encouraged to explore and develop critically through their own research. Secondly, there is a need to guard against an over-emphasis on pedagogy within practitioner research, and that balance is achieved across the gambit of research conducted in the field.

Geographical enquiry, and progression within school geography, are two areas ripe for such development. In both cases, central to understanding the practitioner perspective is a focus on knowledge construction and disciplinary thinking. This is of international concern, as evidenced in the international interest in the US based National Centre for Research in Geography Education's focus on geo-progressions (Solem, Huynh and Boehm 2015), and a forthcoming publication (Solari, Solem and Boehm, 2017).

There is some work to be done to define the field of geography education, building on the work outlined in this paper, to ensure that geography teachers have a sense of the field, and what areas would benefit from their critical insight. It is also important that geography educators working with and supporting practitioners as they research the field are open to practitioners' observations about how changes influence the practice of geography education. Geography educators then have a role to use these insights to inform their own work, and to disseminate the work of practitioner researchers within geography education.

The international collaboration stressed through the revised Charter for Geography Education and the Declaration on Geography Education Research (IGU-CGE, 2015) is an important move forward here. Research work conducted in centres for geography education (and here it is worth noting specifically the NCRGE, National Centre for Research in Geography Education, and the geography research work conducted at ECNU), as well as on the other programmes similar to the one described here, need to be brought together through a dialogic relationship. It is through paying more attention to the concerns of practitioners, and being less reactive to imposed changes that we can build a coherent body of research worthy of being called field of enquiry. This field can then be used to support practitioners and early career researchers so that when they evaluate these changes in the light of "problems of the day", it is informed by the significant body of work that has preceded them.

\section{References:}


Bednarz, S.W., Heffron, S., \& Huynh, N.T. (Eds.). (2013). A road map for 21st century geography education: Geography education research (A report from the Geography Education Research Committee of the Road Map for 21st Century Geography Education Project). Washington, DC: Association of American Geographers.

Brooks, C. (2010) How does one become a researcher in geography education? International Research in Geographical and Environmental Education. Vol. 19, No. 2, May 2010, 113-116.

Brooks,C., Brant, J.,Abrahams, I, \& Yandell, J, (2012) Valuing initial teacher education at Master's level, Teacher Development: An international journal of teachers' professional development, 16:3, 285-302,

Butt , G (1997) An investigation into the dynamics of the National Curriculum geography working group (1989-1990). Unpublished PhD thesis. University of Birmingham.

Butt, G and Lambert, D (2014) International perspectives on the future of geography education and the role of national standards. International Research in Geographical and Environmental Education. Vol 23, no 1 pp.1-12.

Cain, T. (2010) Music teachers' action research and the development of big k knowledge, International Journal of Music Education, 28, (2), 1-17.

Department for Education and Skills. (2011) Learning Outside the Classroom Manifesto (accessed: http://www.lotc.org.uk/wp-content/uploads/2011/03/G1.-LOtC-Manifesto.pdf)

Goodson, I. F. (1987). School Subjects and Curriculum Change: Studies in Curriculum History 2nd ed.. London: Falmer Press.

Graves, N. "Preface" in Graves, N. Kent , A; Lambert D. Naish, M. And Slater F ( 1989) Research in Geography Education: MA Dissertations 1968-1988. University of London, Institute of Education.

Graves, N. (2001). School Textbook Research: the case of geography 1800-2000. London: Institute of Education.

Kent W. A. (2006) Histories of Geographical Education, International Research in Geographical and Environmental Education, 15:4, 307-323

Kent, W. A. (2004) Windows on geographical education. Inaugural Professorial lecture delivered at the Institute of Education, University of London on 13 October 2004.

Lambert D. One Year's Work: a review of the dissertation work done for the MA in Geography Education in 1986-87. in Graves, N. Kent , A; Lambert D. Naish, M. And Slater F ( 1989) Research in Geography Education: MA Dissertations 1968-1988. University of London, Institute of Education.

Lambert, D. (2010) 'Geography education research and why it matters', International Research in Geographical and Environmental Education, 19: 2, $83-86$ 
Lambert, D. (2015) Research in Geography Education. in Butt, G. (ed) Masterclass in Geography Education: Transforming teaching and learning. London: Bloomsbury.

Lambert, D. (2004). Geography. In J. White Ed., Rethinking the School Curriculum pp. 75-86. Abingdon: RoutledgeFalmer.

Marsden, W. E (1980) Introduction: Geographical Education in its Historical Context: Research Possibilities. In Marsden, W. E. (ed) Historical Perspectives on Geographical Education. IGUCGE with IOE: London.

Marsden, W. E. (1997). On taking the geography out of geographical education. Geography, 823, 241-52.

Marsden, W.E (1984). Research Methods in the History of Geographical Education. in Graves, N.J. (ed) Research and Research Methods in Geographical Education. IGU-CGE with IOE: London.

Morgan, J. (2015) Discussion to Part III, in Butt, G. (ed) Masterclass in Geography Education: Transforming teaching and learning. London: Bloomsbury.

Morgan, J., \& Lambert, D. (2005). Geography: Teaching School Subjects 11-19. London: Routledge.

Naish, M. (1997) The scope of geography: a medium for education, in Tilbury, D. and Williams, M. (eds) Teaching and Learning Geography. London: Routledge. pages 49-58.

Oancea, A and Furlong, J. (2007) Expressions of excellence and the assessment of applied and practice-based research. Research Papers in Education 22(2): 119-37.

Rawling, E. (2001). Changing the Subject: the impact of national policy on school geography 19802000. Sheffield: Geographical Association.

Roberts, M. (2015) Discussion to Part I in Butt, G. (ed) Masterclass in Geography Education: Transforming teaching and learning. London: Bloomsbury.

Roberts, M., (forthcoming). The role of Research in Supporting Teaching and Learning

Roberts, M., (2000). The role of Research in Supporting Teaching and Learning. In Kent WA (ed) Reflective Practice in Geography Teaching. London: Sage.

Sachs, J. (2003). The activist teaching profession. Maidenhead, UK: Open University Press.

Slater, Francis (ed) 1994 Reporting Research in Geography Education Monograph No 1. Institute of Education, University of London: London.

Slater, Francis (ed) 1995 Reporting Research in Geography Education Monograph No 2. Institute of Education, University of London: London.

Slater, Francis (ed) 1996 Reporting Research in Geography Education Monograph No 3. Institute of Education, University of London: London. 
Slater, Francis (ed) 1997 Reporting Research in Geography Education Monograph No 4. Institute of Education, University of London: London.

Slater, Francis and John Bale (eds) 1997 Reporting Research in Geography Education Monograph No 5. Institute of Education, University of London: London.

Solari, O., Solem, M., and Boehm, R. G. (Eds) (2017) Learning Progressions in Geography Education: International Perspectives. London: Springer.

Solem, M., Huynh, N.T., and Boehm, R. G. (Eds) (2015) Learning progressions for maps, geospatial technology, and spatial thinking: A research handbook. Newcastle: Cambridge Scholars Publishing.

Walford, R. (2001). Geography in British Schools 1850-2000. London: Woburn Press.

Whitty, G. (2016) Research and Policy in Education. London: UCL IOE Press.

Yoshimizu, H. (2015) Trends in Japanese Geography Education Research in Recent Years. in Ida, Y., Yuda, M., Shimura, T., Ike, S., Ohnishi, K., Oshima, H. (eds) Geography Education in Japan. Tokyo: Springer. pages 175-184.

\footnotetext{
'I am a graduate of the programme (completing my dissertation in 1993), as are several of my colleagues (Fargher, Mitchell, Rayner, Hammond, Flaxman). I have had a period as leader of the programme (from 2007 to 2011) when I revalidated the programme and further developed the online learning component.
} 